\title{
Breast feeding, parental allergy and asthma in children followed for 8 years. The PIAMA birth cohort study
}

\author{
S Scholtens, ${ }^{1}$ A H Wijga, ${ }^{2}$ B Brunekreef, ${ }^{1}$ M Kerkhof, ${ }^{3}$ M 0 Hoekstra, ${ }^{4} \mathrm{~J}$ Gerritsen, ${ }^{5}$ \\ R Aalberse, ${ }^{6} \mathrm{~J} \mathrm{C}$ de Jongste, ${ }^{7} \mathrm{H}$ A Smit ${ }^{2}$
}

\section{See Editorial, p 558}

- Additional methods, figures and tables are published online only at http://thorax.bmi.com/ content/vol64/issue7

${ }^{1}$ Institute for Risk Assessment Sciences, Utrecht University, Utrecht, The Netherlands;

${ }^{2}$ Centre for Prevention and Health Services Research, National Institute for Public Health and the Environment, Bilthoven, The Netherlands; ${ }^{3}$ Department of Epidemiology and Bioinformatics, University of Groningen, Groningen, The Netherlands: ${ }^{4}$ Centre for Paediatric Allergology, Wilhelmina Children's Hospital, Utrecht, The Netherlands:

${ }^{5}$ Beatrix Children's Hospital, University Medical Centre Groningen, University of Groningen, The Netherlands;

${ }^{6}$ Sanquin Research, Amsterdam, The Netherlands; ${ }^{7}$ Department of Pediatrics, Division of Respiratory Medicine, Erasmus MC-Sophia, Rotterdam, The Netherlands

Correspondence to: Dr S Scholtens, National Institute for Public Health and the Environment (RIVM), Centre for Prevention and Health Services Research (pb 101), PO Box 1 , 3720 BA Bilthoven, The Netherlands; salome.scholtens@ rivm.nl

Received 19 December 2007 Accepted 2 January 2009

\section{ABSTRACT}

Background: It is unclear how the association between breast feeding and asthma develops with age of the child and how this association over time is influenced by maternal or paternal allergy. These factors - the age of the child and maternal or paternal allergy — might partly explain the conflicting results observed in cross-sectional studies.

Methods: The study population consisted of 3115 Dutch children born in 1996/1997 who participated in the PIAMA (Prevention and Incidence of Asthma and Mite Allergy) birth cohort study. Data on breast feeding and asthma (based on wheeze, dyspnoea and prescription of inhaled steroids) were collected by yearly questionnaires. At 8 years, specific immunoglobulin E (lgE) to airborne allergens and bronchial responsiveness were measured. Data were analysed by logistic regression and generalised estimating equations (GEEs), and stratified by maternal and paternal allergic status.

Results: $35 \%(n=1081)$ of the children were breast fed for $>16$ weeks. At 8 years of age, $12.6 \%(n=392)$ had asthma. Breast feeding ( $>16$ weeks vs no breast feeding) was significantly associated with a lower asthma prevalence from 3 to 8 years of age, in children of both non-allergic and allergic mothers. The inverse association between breast feeding and sensitisation to airborne allergens at 8 years was non-significant. Breast feeding was not associated with bronchial hyper-responsiveness. No interaction between breast feeding and gender, maternal allergy or paternal allergy was observed in any of the associations.

Conclusions: Breast feeding is associated with a lower asthma risk in children until 8 years of age without evidence of attenuation and regardless of the family history of allergy.

Breast feeding has been advocated for the prevention of asthma, although the results of individual studies are conflicting. The majority of the studies on breast feeding and asthma show a protective association, ${ }^{12}$ although not all. ${ }^{3-5}$ It remains unclear how the association between breast feeding and asthma develops with age of the child and how this association over time is influenced by maternal or paternal allergy. These factors-age of the child and parental allergy-might partly explain the conflicting results observed in studies.

Protective effects of breast feeding on asthma have mostly been reported for young children, whereas in older children no decreased asthma risk has been observed. ${ }^{36-8}$ Two studies suggested that the decreased risk of wheeze in breastfed children was no longer apparent after 2 years of age. ${ }^{68}$ Furthermore, reviews concluded that the protective effect of breast feeding on asthma in children was stronger in children with an allergic heredity, ${ }^{12}$ whereas some individual studies reported no association or even an increased asthma risk in breastfed children with a positive family history. ${ }^{6-11}$ There are indications that the association between breast feeding and asthma is more affected by maternal allergy than by paternal allergy, ${ }^{6}{ }^{12}$ but this needs to be studied in more detail.

In the present study, we assessed the association between breast feeding and asthma from 1 to 8 years of age longitudinally and stratified our analyses on maternal and paternal allergy. Besides parents' reported asthma symptoms of their children, we studied sensitisation to airborne allergens and bronchial hyper-responsiveness (BHR) at 8 years of age.

\section{METHODS}

\section{Study design and study population}

The study population consisted of Dutch children born in 1996/1997 who participated in the PIAMA (Prevention and Incidence of Asthma and Mite Allergy) birth cohort study. In the PIAMA study, mothers were recruited from the general population during pregnancy. A detailed description of the study design has been published previously. ${ }^{13}$ Recruitment took place by means of a validated screening questionnaire on maternal allergy ${ }^{14}$ distributed to pregnant women visiting prenatal clinics in The Netherlands. Based on this screening, 7862 women were invited to participate in the study (Supplementary fig S1). Approximately 50\% of the invited women $(n=4146)$ agreed to participate and gave written informed consent. The mothers were allocated to the intervention arm $(\mathrm{n}=855)$ or to the "natural history" arm $(n=3291)$ of the PIAMA study. Only allergic mothers were included in the intervention study, while in the natural history study allergic $(n=472)$ and non-allergic $(n=2819)$ mothers were included. The intervention study was a double-blind placebo-controlled trial for the evaluation of the use of mite-impermeable mattress and pillow covers.

After birth, the baseline study population consisted of 3963 children.

Questionnaires were sent to the participating parents during pregnancy, at 3 months, and from 1 year of age annually until 8 years of age. At 8 years, a subgroup of the study population $(n=1554)$, 
consisting of almost all the children of allergic mothers and a random sample of the children of non-allergic mothers, was invited for a hospital-based medical examination where a blood sample was collected and the child performed lung function tests. Additionally, 1964 children were invited for a short community-based medical examination or a house visit, where only a blood sample was collected (Supplementary fig S1). The study protocol was approved by the medical ethics committees of the participating institutes and all parents gave written informed consent.

\section{Outcome assessment}

In the questionnaires at 1-8 years of age, the parents were asked whether the child had at least one attack of wheeze in the last year. Data on dyspnoea (at least one episode in the last year) and prescription of inhaled steroids for respiratory or lung problems by a doctor in the last year were collected from 3 to 8 years of age. In the PIAMA study "asthma" was defined as at least one attack of wheeze, and/or one episode of dyspnoea and/ or a prescription of inhaled steroids in the last year. "Chronic asthma" was defined in this study as asthma at 8 years of age in combination with asthma in at least two other years.

In the collected blood samples at 8 years of age, specific immunoglobulin E ( $\operatorname{IgE}$ ) was determined on the following common airborne allergens: house dust mite (Dermatophagoides pteronyssinus), cats, dogs, grass (Dactylis glomerata), birch and Alternaria alternata. Sensitisation to airborne allergens was defined as a specific IgE concentration of at least $0.70 \mathrm{IU} / \mathrm{ml}$ on at least one of the airborne allergens. In the children who participated in the hospital-based medical examination, BHR was determined according to the protocol of the European Community Respiratory Health Survey, ${ }^{15}$ defined as a decrease of $20 \%$ in forced expiratory volume in $1 \mathrm{~s}\left(\mathrm{FEV}_{1}\right)$ at a cumulative dose of $\leqslant 0.61 \mathrm{mg}$ methacholinebromide.

\section{Exposure and confounder assessment}

Duration of breast feeding was assessed by questions on infant feeding in the questionnaires administered at 3 months and at 1 year of age. At 3 months, we asked the parents how long the child was breast fed and if the mother was still breast feeding. If the parents indicated in the questionnaire at 3 months that the mother was still breast feeding, we used data from the 1 year questionnaire to assess the total breast feeding duration. Total breast feeding duration was categorised into "no breast feeding", "1-16 weeks breast feeding" and "breast feeding for more than 16 weeks", because we expected that a certain duration of breast feeding is needed to influence children's asthma risk. Until recently the recommended breast feeding duration in The Netherlands was between 4 and 6 months. Breast feeding was defined as any breast feeding, including partial breast feeding.

Maternal and paternal allergy were reported during pregnancy and were defined as current allergy to house dust mite or pets, current hay fever or ever asthma. For the definition of maternal allergy, the validated screening questionnaire was used that was distributed to the pregnant women visiting a prenatal clinic. The parents reported maternal education, paternal education, maternal age at child birth, the child's birth weight, mode of delivery, maternal smoking during pregnancy (any smoking by the mother during pregnancy after the fourth week of pregnancy) and smoking by anyone in the house at 8 years of age in a questionnaire. Maternal and paternal education was measured as the highest education completed and then divided into three categories (low, intermediate and high education).

\section{Statistical analysis}

Data analysis was conducted using SAS software version 9.1 (SAS Institute, Cary, North Carolina, USA). The association between breast feeding and the outcome variables at 8 years of age were analysed by logistic regression. Generalised estimating equations (GEEs) were used to study the associations between breast feeding and the respiratory outcomes longitudinally, taking into account the correlation between repeated measures in the same individual. A Toepitz working correlation structure fitted the data best. An interaction between breast feeding and age was included in the GEE model to allow the association between breast feeding and the outcome to vary with age.

All associations were adjusted for gender, maternal allergy, paternal allergy, maternal education, maternal smoking during pregnancy and smoking by anyone in the house at 8 years of age. Mode of delivery, birth weight and maternal age were not confounders. The analyses were stratified on maternal and paternal allergy, because these variables were considered to be important potential effect modifiers. The interaction between gender and breast feeding was tested. Although the intervention did not show an effect on sensitisation and atopic symptoms in children at 4 years of age, ${ }^{16}$ effect modification by study group (intervention study and natural history study) was assessed. Any $p$ values $<0.05$ were considered to be statistically significant.

\section{Missing data and multiple imputations}

At 8 years of age, $7.8 \%$ (310/3963) of the children included at baseline were lost to follow-up. In total, 3115 children were included in the analyses (Supplementary methods and fig S1).

Since in the PIAMA study data are unlikely to be "missing completely at random", a complete case analysis may lead to biased results. ${ }^{17} 18$ To avoid bias, missing data were imputed by "multiple imputation". This technique is considered the best available method to deal with missing data. ${ }^{19}$ The details regarding this technique and the results are described in the Supplementary data. All data presented in the Results section and the tables are based on complete case data.

\section{RESULTS}

In the total population, $83.1 \%(n=2588)$ of the children was breast fed and $34.7 \%(n=1081)$ were breast fed for $>16$ weeks (table 1). Children of allergic parents were slightly more likely to be breast fed for $>16$ weeks than children of non-allergic parents, $36.9 \%$ and $32.6 \%$, respectively (data not shown). At 8 years, $12.6 \%(n=392)$ of the children had asthma in the last year (table 2). The prevalence of asthma at 8 years was higher among children of allergic parents than among those of nonallergic parents (table 2). The prevalence of wheeze, dyspnoea and asthma decreased from 3 to 8 years of age, while the prevalence of steroid prescription was constant (Supplementary fig S2).

In the subgroup of children for whom data on sensitisation to airborne allergens were available at 8 years of age $(n=1553)$, $27.5 \% \quad(n=427)$ of the children were sensitised to airborne allergens (table 3 ). The prevalence of sensitisation was higher in children of allergic parents than in children of non-allergic parents (table 3$)$. BHR was present in $40.1 \%(n=344)$ of the children $(\mathrm{n}=858)$. Of the children with asthmatic symptoms at 8 years of age in this subgroup $(n=140), 57.9 \%(n=81)$ had 
Table 1 Characteristics of the study population $(n=3115)$

\begin{tabular}{lcc}
\hline & $\%$ & No \\
\hline Breast feeding duration & & \\
0 weeks & 16.9 & 527 \\
$1-16$ weeks & 48.4 & 1507 \\
$>16$ weeks & 34.7 & 1081 \\
Allergic mother & 28.2 & 877 \\
Allergic father & 30.3 & 944 \\
Gender (\% girls) & 48.6 & 1514 \\
Maternal education level & & \\
$\quad$ Low & 21.2 & 660 \\
Intermediate & 42.3 & 1318 \\
$\quad$ High & 36.5 & 1137 \\
Maternal smoking during pregnancy & 15.5 & 484 \\
Any smoking in the house at 8 years & 16.5 & 515 \\
Born by caesarean section & 8.5 & 261 \\
\hline & Mean & SD \\
\hline Maternal age (years) & 30.6 & 3.8 \\
Birth weight child $(g)$ & 3527 & 533 \\
\hline
\end{tabular}

BHR compared with $36.6 \%(n=263)$ of the children without asthma ( $\mathrm{n}=718)$ (data not shown).

At 8 years, the asthma risk was significantly lower in children breast fed for $>16$ weeks compared with those who were not breas tfed (table 2). The associations between breast feeding and wheeze, dyspnoea and prescription of inhaled steroids were in the same direction, and were significant for dyspnoea and prescription of inhaled steroids. Children breast fed for $>16$ weeks had significantly fewer chronic asthma symptoms (asthma at 8 years of age in combination with asthma in at least two other years). The odds ratio (OR) for a breast feeding duration between 1 and 16 weeks was consistently $<1$ for all outcomes, but not statistically significant. Adjustment for confounders did not change the associations. The point estimates were slightly different for children of allergic and non-allergic mothers, reaching statistical significance in the subgroups of children from non-allergic mothers only (table 2). However, tests for interactions showed that these differences were not significant (for maternal allergy $p=0.34$ and $p=0.14$ for $0-16$ weeks breast feeding and $>16$ weeks breast feeding, respectively, and for paternal allergy $p=0.35$ and $p=0.59$ for 0 16 weeks breast feeding and $>16$ weeks breast feeding, respectively). This suggests that the overall results were not driven by those in one subgroup only. No interaction was observed between maternal asthma and breast feeding. The association between breast feeding and asthma was similar for boys and girls, also after stratification by maternal allergy, paternal allergy or maternal asthma.

Breast feeding for $>16$ weeks was inversely associated with sensitisation to airborne allergens at 8 years (table 3), although the association was not significant. No interaction was observed between breast feeding and maternal or parental allergy. No association was observed between breast feeding for $>16$ weeks and BHR in the total population (OR $=0.94,95 \%$ CI 0.61 to $1.44, p=0.76)$, or in children of non-allergic or allergic mothers or fathers (data not shown).

The longitudinal analyses accounting for repeated measurements (GEE) showed that breast feeding for $>16$ weeks, compared with no breastfeeding, was associated with a lower risk of wheeze (Supplementary fig S3) and asthma (fig 1) in all years, although not significantly at each year. Figure 2 shows the associations between breast feeding for $>16$ weeks and asthma from 3 to 8 years of age stratified by maternal allergy. In both groups, breast feeding was associated with a lower asthma risk in all years.

Breast feeding duration and asthma prevalence at 8 years did not differ between the children of allergic mother in the intervention study and in the natural history study (Supplementary table S1). The associations between breast feeding and the asthma symptoms did not differ between the intervention and the natural history study, and the interaction between study group and breast feeding was not significant (data not shown). Therefore, all results were reported for the two groups combined.

The results based on imputed data are presented in the Supplementary data.

\section{DISCUSSION}

Children breast fed for $>16$ weeks had a lower asthma risk at 3-8 years of age. Breast feeding was borderline significantly

Table 2 Prevalence of wheeze, dyspnoea, prescription of inhaled steroids, asthma and chronic asthma at 8 years of age and adjusted association with breast feeding (total study population, $\mathrm{n}=3115$ )

\begin{tabular}{|c|c|c|c|c|c|c|c|c|c|c|}
\hline & \multirow{2}{*}{\multicolumn{2}{|c|}{ Prevalence }} & \multicolumn{6}{|c|}{ Prevalence by breast feeding duration } & \multirow{3}{*}{$\begin{array}{l}\text { BF 1-16 weeks, adjusted } \dagger \\
\text { OR }(95 \% \mathrm{CI})\end{array}$} & \multirow{3}{*}{$\begin{array}{l}\text { BF }>16 \text { weeks, adjusted } \dagger \\
\text { OR }(95 \% \text { Cl })\end{array}$} \\
\hline & & & \multicolumn{2}{|c|}{ None } & \multicolumn{2}{|c|}{ 1-16 weeks } & \multicolumn{2}{|c|}{$>16$ weeks } & & \\
\hline & $\%$ & No & $\%$ & No & $\%$ & No & $\%$ & No & & \\
\hline Wheeze & 6.3 & 196 & 7.0 & 37 & 6.9 & 104 & 5.1 & 55 & $0.93(0.63$ to 1.38$)$ & $0.66(0.42$ to 1.04$)$ \\
\hline Dyspnoea & 8.5 & 265 & 9.9 & 52 & 9.1 & 137 & 7.0 & 76 & $0.87(0.61$ to 1.22$)$ & $0.64(0.43 \text { to } 0.94)^{*}$ \\
\hline Prescription inhaled steroids & 6.4 & 200 & 8.5 & 45 & 7.0 & 105 & 4.6 & 50 & $0.77(0.53$ to 1.12$)$ & $0.50(0.32 \text { to } 0.77)^{*}$ \\
\hline Asthma & 12.6 & 392 & 15.4 & 81 & 13.5 & 203 & 10.0 & 108 & $0.82(0.61$ to 1.09$)$ & $0.57(0.41 \text { to } 0.80)^{*}$ \\
\hline Chronic asthma§ & 8.3 & 257 & 9.5 & 50 & 8.8 & 133 & 6.9 & 74 & $0.87(0.62$ to 1.24$)$ & $0.65(0.44 \text { to } 0.96)^{*}$ \\
\hline \multicolumn{11}{|c|}{$\begin{array}{l}\text { Asthma stratified by allergy mother/ } \\
\text { father: }\end{array}$} \\
\hline Non-allergic mother $(n=2238)$ & 10.3 & 231 & 14.0 & 56 & 11.1 & 121 & 7.3 & 54 & $0.78(0.55$ to 1.11$)$ & $0.52(0.34 \text { to } 0.78)^{*}$ \\
\hline Allergic mother $(n=877)$ & 18.4 & 161 & 19.5 & 25 & 19.9 & 82 & 16.1 & 54 & $0.95(0.57$ to 1.59$)$ & $0.70(0.41$ to 1.22$)$ \\
\hline Non-allergic father $(n=2171)$ & 10.4 & 226 & 12.2 & 47 & 11.4 & 120 & 8.0 & 59 & $0.91(0.63$ to 1.31$)$ & $0.62(0.40 \text { to } 0.94)^{*}$ \\
\hline Allergic father $(n=944)$ & 17.6 & 166 & 23.9 & 34 & 18.2 & 83 & 14.2 & 49 & $0.69(0.43$ to 1.10$)$ & $0.51(0.30 \text { to } 0.86)^{*}$ \\
\hline
\end{tabular}

$* \mathrm{p}<0.05$.

$\S$ Defined as asthma at 8 years of age in combination with asthma in at least two previous years.

DDefined as at least one attack of wheeze, one episode of dyspnoea or a prescription of inhaled steroids in the last year.

$\uparrow$ No breast feeding is reference. Associations are adjusted for gender, maternal allergy, paternal allergy, maternal education, maternal smoking during pregnancy, and smoking by anyone in the house at 8 years.

$\mathrm{BF}$, breast feeding. 
Table 3 Prevalence of asthma and sensitisation to airborne allergens at 8 years of age and adjusted association with breast feeding (subgroup of the total study population, $\mathrm{n}=1553$ )

\begin{tabular}{|c|c|c|c|c|c|c|c|c|c|c|}
\hline & \multirow{2}{*}{\multicolumn{2}{|c|}{ Prevalence }} & \multicolumn{6}{|c|}{ Prevalence by breast feeding duration } & \multirow{3}{*}{$\begin{array}{l}\text { BF 1-16 weeks, adjusted } \dagger \\
\text { OR (95\% CI) }\end{array}$} & \multirow{3}{*}{$\begin{array}{l}\text { BF }>16 \text { weeks, adjusted } \dagger \\
\text { OR }(95 \% \text { CI })\end{array}$} \\
\hline & & & \multicolumn{2}{|l|}{ None } & \multicolumn{2}{|c|}{$1-16$ weeks } & \multicolumn{2}{|c|}{$>16$ weeks } & & \\
\hline & $\%$ & No & $\%$ & No & $\%$ & No & $\%$ & No & & \\
\hline Asthma & 14.0 & 217 & 14.2 & 34 & 15.9 & 115 & 11.5 & 68 & $1.12(0.73$ to 1.71$)$ & $0.77(0.48$ to 1.22$)$ \\
\hline Sensitisation§ & 27.5 & 427 & 29.6 & 71 & 27.9 & 202 & 26.2 & 154 & $0.89(0.64$ to 1.24$)$ & $0.80(0.57$ to 1.14$)$ \\
\hline Asthma and sensitisation & 8.7 & 135 & 8.3 & 20 & 10.2 & 74 & 7.0 & 41 & $1.19(0.70$ to 2.01$)$ & $0.75(0.42$ to 1.34$)$ \\
\hline $\begin{array}{l}\text { Asthma without } \\
\text { sensitisation }\end{array}$ & 5.3 & 82 & 5.8 & 14 & 5.7 & 41 & 4.6 & 27 & $1.00(0.53$ to 1.89$)$ & 0.84 (0.42 to 1.68$)$ \\
\hline \multicolumn{11}{|l|}{$\begin{array}{l}\text { Sensitisation§ stratified } \\
\text { by allergy mother/father: }\end{array}$} \\
\hline $\begin{array}{l}\text { Non-allergic mother } \\
(\mathrm{n}=986)\end{array}$ & 23.6 & 233 & 22.8 & 36 & 25.0 & 116 & 22.3 & 81 & $1.17(0.75$ to 1.82$)$ & 1.03 (0.64 to 1.64$)$ \\
\hline Allergic mother $(n=567)$ & 34.2 & 194 & 42.7 & 35 & 33.1 & 86 & 32.4 & 73 & $0.62(0.36$ to 1.05$)$ & $0.58(0.33$ to 1.01$)$ \\
\hline $\begin{array}{l}\text { Non-allergic father } \\
(\mathrm{n}=1064)\end{array}$ & 24.2 & 257 & 26.9 & 46 & 24.7 & 122 & 22.3 & 89 & 0.88 (0.59 to 1.32$)$ & $0.76(0.49$ to 1.16$)$ \\
\hline Allergic father $(n=489)$ & 34.8 & 170 & 36.2 & 25 & 34.8 & 80 & 34.2 & 65 & 0.91 (0.51 to 1.63$)$ & 0.88 (0.48 to 1.63$)$ \\
\hline
\end{tabular}

${ }^{*} \mathrm{p}<0.05$.

$\dagger$ No breastfeeding is reference. Associations are adjusted for gender, maternal allergy, paternal allergy, maternal education, maternal smoking during pregnancy, and smoking by anyone in the house at 8 years.

tDefined as at least one attack of wheeze, one episode of dyspnoea or a prescription of inhaled steroids in the last year.

$\S$ Defined as a specific immunoglobulin $\mathrm{E}$ concentration of at least $0.70 \mathrm{IU} / \mathrm{ml}$ on at least one of the airborne allergens.

$B F$, breast feeding.

associated with a lower prevalence of sensitisation to airborne allergens and was not associated with BHR at 8 years of age.

The results corresponded with the conclusions of reviews of cross-sectional studies on breast feeding and asthma. ${ }^{12}$ In addition, because of the longitudinal analysis, we could show that breast feeding was protective against asthma throughout the age range 1-8 years of age, in children of both allergic and non-allergic mothers. Our results also show that cross-sectional analysis at a certain age could have led to the conclusion that associations were different in children of allergic and nonallergic mothers, due to small variations in the associations with age of the child (fig 1). Also, we showed that a relatively long breast feeding duration was needed to show a significant effect.

Two other longitudinal studies showed a decreased risk of wheeze, but only until 2 years of age. ${ }^{6}$ In contrast to our results, Sears et al showed an increased asthma risk in breastfed children from 9 years of age. ${ }^{3}$ In their study, $>4$ weeks breast

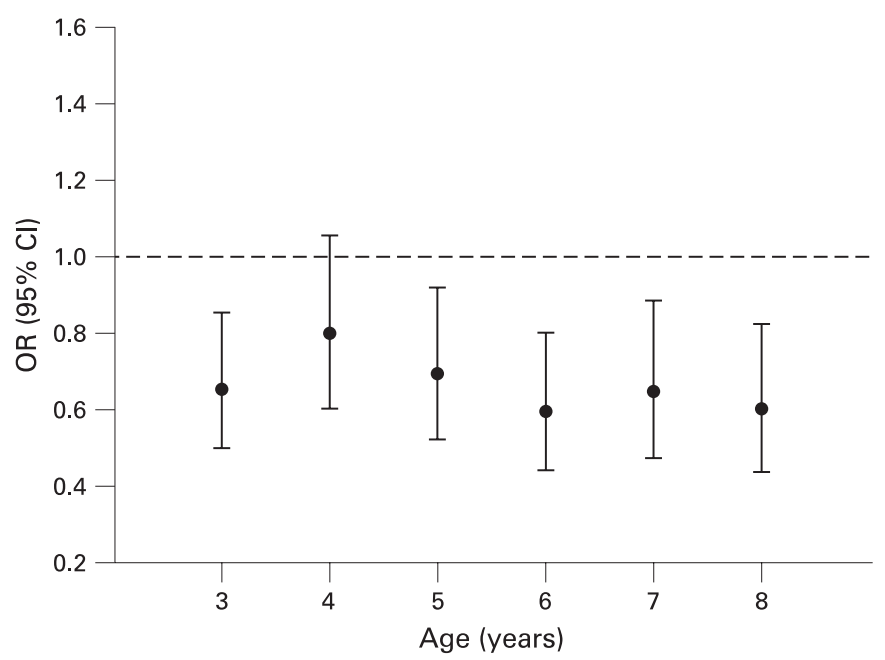

Figure 1 Adjusted associations between breast feeding ( $>16$ weeks vs no breast feeding) and asthma at 3-8 years of age in the total population $(\mathrm{n}=3115)$.
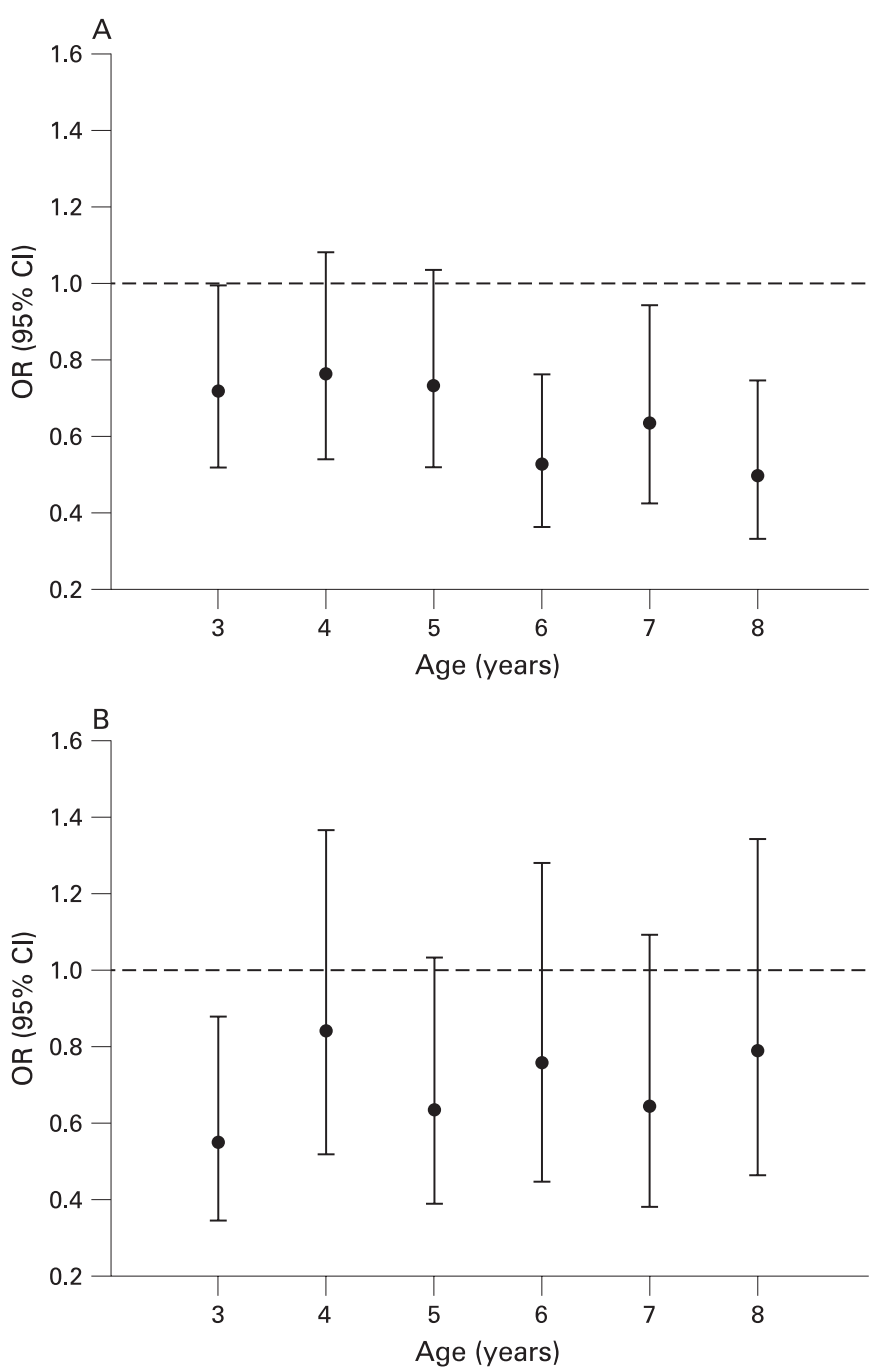

Figure 2 Adjusted associations between breast feeding ( $>16$ weeks vs no breast feeding) and asthma at 3-8 years of age in children of (A) non-allergic mothers $(n=2238)$ and $(B)$ allergic mothers $(n=877)$. 
feeding was compared with $<4$ weeks, and breast feeding duration was assessed retrospectively when the child was 3 years of age, which might have caused the differential results.

The protective association between breast feeding and asthma was observed in children both with and without a family history of allergy. We did not find evidence for a differential effect of maternal or paternal allergy or asthma on the association between breast feeding and asthma. Others have also reported no interaction between family history of allergy and breast feeding in the inverse association between breast feeding and asthma. ${ }^{10} 20$

Some studies have observed a more pronounced protective effect of breast feeding on asthma in children without a positive family history of allergy, ${ }^{9-11}$ while Wright et al ${ }^{4}$ observed no association between breast feeding and asthma in children of non-asthmatic mothers and an increased asthma risk in breastfed children of asthmatic mothers at 13 years of age.

A recent paper by Mandhane et a ${ }^{21}$ suggested an interaction between gender of the child, parental atopy and breast feeding in the association between breast feeding and asthma in a study in 13-year-old children. We did not observe an interaction between gender and breast feeding, or between gender, parental allergy and breast feeding in the association between breast feeding and asthma.

Our study observed a lower risk for sensitisation to airborne allergens among breastfed children. In the literature, a lower as well as a higher sensitisation risk in breastfed children compared with formula-fed children has been reported. ${ }^{32}$ Wright et al found a lower total serum IgE in breastfed children of mothers with low serum IgE, but not in mothers with high serum IgE. ${ }^{23}$ Sensitisation to airborne allergens is a risk factor for asthma, and in particular sensitised children who wheeze tend to develop chronic asthma. ${ }^{24}$ No association was observed between breast feeding and BHR, although BHR is thought to be an important indicator for asthma. ${ }^{25}$ Possibly BHR as a single indicator was not sensitive enough to discriminate between children with and without asthma at this age, ${ }^{25}{ }^{26}$ although two studies have found a decreased risk of BHR in breastfed children. $^{27} 28$

Strengths of the present study were the longitudinal study design, the follow-up until 8 years of age with repeated data collection, and the large study population with a low attrition rate. In addition to data on asthma symptoms such as wheeze and dyspnoea, we collected data on prescription of inhaled steroids, sensitisation to airborne allergens and BHR. Data on maternal and paternal allergy made it possible to study the differential effect on the association. Since breast feeding duration was reported prospectively, the probability of recall bias was eliminated

Unfortunately, no data were available on exclusive breast feeding. However, using exclusive breast feeding instead of any breast feeding would probably strengthen the associations. Our asthma definition was based on wheeze, dyspnoea and prescription of inhaled steroids reported by the parents. These factors are important indicators for asthma in children, and the association between breast feeding and these individual factors was similar to the association between breast feeding and the combined asthma variable.

Allergic parents possibly recognise asthma symptoms in their children more easily than non-allergic parents and report asthma symptoms sooner. Although such a bias could partially explain the difference in asthma prevalence in children of allergic and non-allergic parents, it does not affect the association between breast feeding and asthma. Reverse causation due to a higher likelihood of allergic parents to breast feed because of the protective association with allergy and asthma is less likely in our study since the difference in breast feeding prevalence between allergic and non-allergic parents was small. Mothers of children who develop early allergic or asthmatic symptoms, such as wheeze or eczema, might be more motivated to breast feed longer, which weakens the real protective association between prolonged breast feeding and asthma in children at later ages.

Asthma is difficult to diagnose at an early age, because wheeze and dyspnoea are common symptoms of respiratory infections in young children. Since breast feeding has been associated with fewer early respiratory infections, ${ }^{29-31}$ the observed association between breast feeding and asthma at early ages might be mediated by the protective effect of breast feeding on respiratory infections. However, wheeze, dyspnoea and use of inhaled steroids in children of 8 years of age are more suggestive of asthma than of infections. The fact that the prevalence of asthma, wheeze and dyspnoea no longer decreased from 7 years of age made us confident that the symptoms reported by the parents were due to asthma rather than respiratory infections. Also, breastfed children were less likely to have asthma in combination with sensitisation. These children are especially prone to develop chronic symptoms. ${ }^{24}$

The association between breast feeding and wheeze was in the same direction as the other outcomes, but did not reach significance. Presumably, the variable "wheeze" was not specific enough as an individual symptom and is mixed with nonasthmatic wheeze and therefore has a weaker association with breast feeding. The strongest association was observed between breast feeding and prescription of inhaled steroids by a doctor. A prescription of inhaled steroids might be a more specific indicator of asthma. A follow-up of the children after puberty is needed to study whether the association between breast feeding and asthma remains when the child grows older.

Several biological mechanisms have been suggested to explain the lower asthma risk in breastfed children. ${ }^{32}$ Breast milk is thought to contain immunomodulatory factors that influence the maturation of the infant's immune system. ${ }^{33}$ Also, it has been suggested that breast feeding stimulates the maturation of the immature gastrointestinal mucosa of the newborn infant and that breast feeding leads to a differential intestinal microflora compared with formula-fed infants, ${ }^{34}$ which could influence the maturation of the naive immune system. ${ }^{35}$ Breastfed children have fewer respiratory infections in early life, which could also decrease the asthma risk. ${ }^{3032} \mathrm{We}$ hypothesised that one of the possible pathways whereby breast feeding may reduce the risk of asthma is by reducing the risk of sensitisation, because the association between breast feeding and sensitisation was borderline significant and the association with allergic asthma (asthma symptoms and sensitisation) was significant.

In conclusion, in the present study, breast feeding is associated with a lower asthma risk in children until 8 years of age without evidence of attenuation of the association and regardless of the family history of allergy.

Competing interests: None.

Ethics approval: The study protocol was approved by the medical ethics committees of the participating institutes.

\section{REFERENCES}

1. van Odijk J, Kull I, Borres MP, et al. Breastfeeding and allergic disease: a multidisciplinary review of the literature (1966-2001) on the mode of early feeding in infancy and its impact on later atopic manifestations. Allergy 2003;58:833-43. 
2. Gdalevich M, Mimouni D, Mimouni M. Breast-feeding and the risk of bronchial asthma in childhood: a systematic review with meta-analysis of prospective studies. J Pediatr 2001;139:261-6.

3. Sears MR, Greene JM, Willan AR, et al. Long-term relation between breastfeeding and development of atopy and asthma in children and young adults: a longitudinal study. Lancet 2002;360:901-7

4. Wright AL, Holberg CJ, Taussig LM, et al. Maternal asthma status alters relation of infant feeding to asthma in childhood. Adv Exp Med Biol 2000;478:131-7.

5. Scholtens S, Gehring U, Brunekreef B, et al. Breastfeeding, weight gain in infancy, and overweight at seven years of age: the prevention and incidence of asthma and mite allergy birth cohort study. Am J Epidemiol 2007;165:919-26.

6. Wright AL, Holberg CJ, Taussig LM, et al. Factors influencing the relation of infant feeding to asthma and recurrent wheeze in childhood. Thorax 2001;56:192-7.

7. Lewis S, Richards D, Bynner J, et al. Prospective study of risk factors for early and persistent wheezing in childhood. Eur Respir J 1995:8:349-56.

8. Burr ML, Limb ES, Maguire MJ, et al. Infant feeding, wheezing, and allergy: a prospective study. Arch Dis Child 1993;68:724-8.

9. Rothenbacher D, Weyermann M, Beermann C, et al. Breastfeeding, soluble CD14 concentration in breast milk and risk of atopic dermatitis and asthma in early childhood: birth cohort study. Clin Exp Allergy 2005;35:1014-21.

10. Kull I, Almqvist C, Lilja G, et al. Breast-feeding reduces the risk of asthma during the first 4 years of life. J Allergy Clin Immunol 2004;114:755-60.

11. Obihara CC, Marais BJ, Gie RP, et al. The association of prolonged breastfeeding and allergic disease in poor urban children. Eur Respir $\mathrm{J}$ 2005;25:970-7.

12. Leme AS, Hubeau C, Xiang $Y$, et al. Role of breast milk in a mouse model of maternal transmission of asthma susceptibility. J Immunol 2006:176:762-9.

13. Brunekreef B, Smit J, de Jongste J, et al. The prevention and incidence of asthma and mite allergy (PIAMA) birth cohort study: design and first results. Pediatr Allergy Immunol 2002;13(Suppl 15):55-60.

14. Lakwijk N, Van Strien RT, Doekes G, et al. Validation of a screening questionnaire for atopy with serum IgE tests in a population of pregnant Dutch women. Clin Exp Allergy 1998;28:454-8.

15. Burney PG, Luczynska C, Chinn S, et al. The European Community Respiratory Health Survey. Eur Respir J 1994;7:954-60.

16. Corver K, Kerkhof M, Brussee JE, et al. House dust mite allergen reduction and allergy at 4 yr: follow up of the PIAMA-study. Pediatr Allergy Immunol 2006;17:32936.

17. Rubin DB. Multiple imputation for nonresponse in surveys. New York: John Wiley and Sons, 1987.

18. Schafer JL. Analysis of incomplete multivariate data. London: Chapman \& Hall, 1997.
19. Klebanoff MA, Cole SR. Use of multiple imputation in the epidemiologic literature. Am J Epidemiol 2008;168:355-7.

20. Oddy WH, Peat JK, de Klerk NH. Maternal asthma, infant feeding, and the risk of asthma in childhood. J Allergy Clin Immunol 2002;110:65-7.

21. Mandhane PJ, Greene JM, Sears MR. Interactions between breast-feeding, specific parental atopy, and sex on development of asthma and atopy. J Allergy Clin Immunol 2007; 119:1359-66.

22. Oddy WH, Holt PG, Sly PD, et al. Association between breast feeding and asthma in 6 year old children: findings of a prospective birth cohort study. BMJ 1999;319:815-9.

23. Wright AL, Sherrill D, Holberg CJ, et al. Breast-feeding, maternal IgE, and total serum IgE in childhood. J Allergy Clin Immunol 1999;104:589-94.

24. Illi S, von Mutius E, Lau S, et al. Perennial allergen sensitisation early in life and chronic asthma in children: a birth cohort study. Lancet 2006;368:763-70.

25. de Meer G, Marks GB, Postma DS. Direct or indirect stimuli for bronchial challenge testing: what is the relevance for asthma epidemiology? Clin Exp Allergy 2004;34:9-16

26. Remes ST, Pekkanen J, Remes K, et al. In search of childhood asthma: questionnaire, tests of bronchial hyperresponsiveness, and clinical evaluation. Thorax 2002; 57:120-6.

27. Eneli IU, Karmaus WK, Davis S, et al. Airway hyperresponsiveness and body mass index: the Child Health and Environment Cohort Study in Hesse, Germany. Pediatr Pulmonol 2006;41:530-7.

28. Futrakul S, Deerojanawong J, Prapphal N. Risk factors of bronchial hyperresponsiveness in children with wheezing-associated respiratory infection. Pediatr Pulmonol 2005;40:81-7.

29. Wright AL, Holberg CJ, Martinez FD, et al. Breast feeding and lower respiratory tract illness in the first year of life. Group Health Medical Associates. BMJ 1989;299:946-9.

30. Chantry CJ, Howard CR, Auinger P. Full breastfeeding duration and associated decrease in respiratory tract infection in US children. Pediatrics 2006;117:425-32.

31. Oddy WH, de Klerk NH, Sly PD, et al. The effects of respiratory infections, atopy, and breastfeeding on childhood asthma. Eur Respir J 2002;19:899-905.

32. Oddy WH. A review of the effects of breastfeeding on respiratory infections, atopy, and childhood asthma. J Asthma 2004;41:605-21.

33. Field CJ. The immunological components of human milk and their effect on immune development in infants. J Nutr 2005;135:1-4.

34. Mountzouris KC, McCartney AL, Gibson GR. Intestinal microflora of human infants and current trends for its nutritional modulation. $\mathrm{Br} J$ Nutr 2002;87:405-20.

35. Gronlund MM, Arvilommi $\mathrm{H}$, Kero $\mathrm{P}$, et al. Importance of intestinal colonisation in the maturation of humoral immunity in early infancy: a prospective follow up study of healthy infants aged 0-6 months. Arch Dis Child Fetal Neonatal Ed 2000;83:F186-92.

\section{BMJ Careers Fair}

2-3 October 2009, Business Design Centre, London, UK

9-10 October 2009, Thinktank, Birmingham, UK

BMJ is the largest organiser of medical recruitment fairs across the UK. This year we are organising two careers fairs, in partnership with the London Deanery on 2-3 October in London, and the West Midlands Deanery on 9-10 October in Birmingham.

Whatever your grade or specialty there is a careers fair for you. You can:

- attend seminars on topics such as CV writing, interview skills, planning your career and working abroad

- visit exhibition stands to get careers advice, find a new job, identify alternative career pathways

It's free to attend the exhibition if you register online in advance. There is a small fee for attending our seminar programme.

Register online today at www.careersfair.bmj.com 